Alternative entry points for adaptation: examples from Vanuatu

Ross Westoby, Rachel Clissold and Karen E McNamara

$\underline{\text { Affiliations }}$

Dr Ross Westoby

Griffith Institute for Tourism

Griffith University, Gold Coast, Australia

Rachel Clissold

School of Earth and Environmental Sciences

The University of Queensland, Brisbane, Australia

Dr Karen E McNamara (corresponding author)

School of Earth and Environmental Sciences

The University of Queensland, Brisbane, Australia

E: karen.mcnamara@uq.edu.au

P: +61733656069 


\title{
Alternative entry points for adaptation: examples from Vanuatu
}

\begin{abstract}
As climate change accelerates, effective adaptation is an urgent and unavoidable priority. Bottom-up approaches such as community-based adaptation have been portrayed as the panacea. Recent studies are, however, highlighting the ongoing and inherent issues with normative 'community' conceptualisations that assume a geographically-bound, temporallyfixed and harmonious unit. Despite documentation on the negative impact these problematic assumptions can have on adaptation outcomes, adaptation at the community scale remains the preferred option for project delivery in highly exposed places such as the Pacific Islands region. More creative entry points that are less charged with problematic assumptions are needed at the local scale. This paper draws from three examples in Vanuatu to offer compelling alternative entry points for adaptation: 1) a rural technical college embedded within an Anglican mission village, 2) a whole-of-island approach, and 3) the 'collective of vendors' at marketplaces. We offer hope by identifying ways to expand on and complement existing, restricted notions of 'community' and, through this, improve adaptation outcomes.
\end{abstract} Key words: adaptive capacity, climate change, community-based, Pacific Islands, scale, Vanuatu 


\section{Introduction}

Climate change impacts are growing in magnitude and frequency with marked impacts across the globe (IPCC, 2014). Effective adaptation is an urgent and unavoidable priority as climate change accelerates and makes it increasingly difficult for vulnerable countries to meet adaptation needs (IPCC, 2014). Despite this urgency, adaptation activity in highly exposed regions like the Pacific Islands have had minimal progress towards intended objectives to date (Nunn \& Kumar, 2019) and there has been uncertainty around whether community capacities to cope in the long-term have improved (Hay \& Mimura, 2013; McNamara, 2013). In particular, top-down and state-centric approaches are generally considered ineffective and unpopular, rendering bottom-up, community-based approaches the preferred option for project delivery (Agrawal \& Gibson, 1999; Boyd et al., 2009). Community-based adaptation (CBA) is often a 'soft' approach that, in principle, should focus on underlying vulnerabilities and have synergies with development, thereby taking into consideration the social, political, environmental and economic spheres of communities (Heltberg et al., 2009; Barnett \& O’Neill, 2010; Buggy \& McNamara, 2016). CBA is considered people-centered, participatory and grassroots, and it is the associated moral claim of 'working with the people' that has given rise to a perception that "it is difficult to do much wrong when involving the 'community"' (Titz et al., 2018: 72).

The portrayal of CBA as a panacea has meant that it can be uncritically implemented, whereby limitations, challenges and nuances are overlooked (Buggy \& McNamara, 2016; Ford et al., 2016). One of the key challenges emerging from the growing body of studies assessing CBA effectiveness is the ongoing and inherent problems related to the concept of ‘community’ (see e.g. Yates, 2014; Buggy \& McNamara, 2016; Clissold \& McNamara, 2019; Westoby et al., 2019; McNamara et al., 2020). Normative conceptualisations of ‘community' - as a small, fixed scale based on geography - are wrought with assumptions 
that can render adaptation ineffective or even maladaptive (Buggy \& McNamara, 2016; Ford et al., 2016) ${ }^{1}$. To improve outcomes, we must move beyond normative conceptions and explore more meaningful and radical entry points for adaptation at the local scale (Mulligan, 2015; Titz et al., 2018; Westoby et al., 2019). Alternative entry points are, however, rarely documented, especially for highly exposed regions like the Pacific (see exception Remling \& Veitayaki, 2016) that have many communities at the vanguard of adaptation. This paper explores some compelling alternative entry points for adaptation delivery and improved outcomes for local people in Vanuatu. In this way, we do not necessarily call for abandoning the use of CBA and community scales altogether but rather attempt to offer hope by identifying alternative entry points that can be used to expand on and complement existing notions of 'community' in adaptation work.

A study of this nature is critical to Pacific Island nations as locally grounded responses using local and traditional capital and knowledge - have been widely encouraged in the region (Warrick et al., 2017; Nalau et al., 2018; Dacks et al., 2019) and tend to be the adaptive preferences of locals (Narayan et al., 2020). Although CBA is often presumed to be a suitable approach in this context, evidence suggests that normative conceptualisations of 'community' have not necessarily lent themselves neatly to effective adaptation practice at the local scale in the Pacific Islands (e.g. see Buggy \& McNamara, 2016; Clissold \& McNamara, 2019; Westoby et al., 2019). We, therefore, need contextually appropriate alternative entry points that can be used to expand on and complement the traditional, rigid conceptualisation of 'community' that have proved problematic in the past. This requires actively engaging with the local cultural context and its unique complexities and diversities.

\section{Literature review}

\footnotetext{
${ }^{1}$ Please note that from herein, when we refer to 'community', we refer to its normative conceptualisation and associated assumptions.
} 
There are a multitude of problematic assumptions around the normative notion of 'community' employed by donors, implementing agencies and other actors. This is hardly new with sociologists having agonised over the multiple meanings of 'community' for decades (Mulligan, 2015). In particular, there is a propensity to limit our construct of 'community' to a small, fixed scale that is geographically circumscribed (Lane \& McDonald, 2005; Westoby \& Dowling, 2013). This is partnered with a tendency to romanticise them as unified and harmonious through assuming homogenous social structures (Yates, 2014; Titz et al., 2018) or shared norms and common interests (Agrawal \& Gibson, 1999).

Although normative conceptualisations provide a convenient, readily identifiable bordered space for external actors, this has been considered a weak foundation on which to base policy and deliver programs (Agrawal \& Gibson, 1999). Such conceptualisations and their associated assumptions detach the 'community' from the inherent socio-political context (Westoby \& Dowling, 2013), mask vested interests and relations of exploitation, and become a 'totalising mechanism' that conceals heterogeneity (Young, 1990; Hudson, 2012). This can be misleading and dangerous because all 'communities' encompass 'fault-lines' (i.e. preexisting vulnerabilities, divisions and conflicts) which can worsen in the face of stress to diminish prospects for collaboration, unity and persistence (Mulligan, 2015; Mulligan et al., 2016). Other problematic assumptions that emerge under this normative framing of 'community' include "spontaneity instead of mediation, emotions instead of reasoning... and stability instead of change" (Young, 1990 and Wiesenfield, 1996 in Mannarini \& Fedi, 2009: 212). In sum, the complexity, diversity and multifaceted nature of places and spaces as well as the multiplicity of identity are being sidelined for fast policy that requires rapid and reductionist assessments (Cannon, 2008; Titz et al., 2018).

There are some key emerging lessons from community-based research to consider when identifying alternative entry points beyond the small, geographically fixed scale. The first is 
the urgent need to reframe 'community' as more than just the place where projects are operationalised, but as a site where the socio-political context and its multiple actors with multiple interests are understood, worked with and transformed (Agrawal \& Gibson, 1999; Buggy \& McNamara, 2016). This helps ensure that 'community' issues are not built into projects, that maladaptation is avoided, and that project goals and outcomes do not entrench existing inequalities (Buggy \& McNamara, 2016). This is important in the Pacific context as assumptions of undifferentiated identity and harmony within the 'community' have previously led to elite capture (Buggy \& McNamara, 2016; Westoby et al., 2019), which hinders adaptation success by occasioning disagreements, strained cooperation and loss of respect for initiatives (Buggy \& McNamara, 2016). To adequately integrate local sociopolitical contexts in the Pacific, studies also illustrate how we cannot overlook the role of religion, spirituality and the church in shaping power relations and collective identity, as these can enable or constrain local agency and motivations to pursue adaptive outcomes (Kuruppu, 2009; Clissold \& McNamara, 2019; Piggott-McKellar et al., 2019; Luetz \& Nunn, 2020). Differences in gender (Ensor, 2016; Clarke et al., 2019), immigrant status, clans, household ancestral access to resources (Warrick et al., 2017) and peripherality (Nunn et al., 2014) can also give rise to heterogeneity in Pacific communities and should be considered in any alternative entry point at the local scale.

Community-based conservation research has taught us that small, territorially fixed 'communities' may be inappropriate managers for resources that are spread over large geographical areas (Agrawal, 1999; Agrawal \& Gibson, 1999; de Beer, 2013). Researchers are increasingly championing alternative scales and focuses for community-based adaptation, such as the seascape, ecosystem (Jeans et al., 2014; Reid, 2016; Girot et al., 2016) or, in the Pacific context, a whole island (Remling \& Veitayaki, 2016). These alternative scales remind us that demarcations between social and ecological systems are arbitrary (Berkes \& Folke, 
1998; Berkes et al., 2003). The entry point or system boundaries for adaptation should depend on the problem context and encapsulate a series of interacting and linked elements (i.e. a social-ecological system), including ecosystems, local knowledge, people and technology and institutions (Berkes \& Folke, 1998; Berkes et al., 2003). Focusing on larger, complex scales in this way can help transcend 'community' and national boundaries, and through this, reveal negative externalities as well as better account for conflicts between 'communities' (Chishakwe et al., 2012). Bringing together the resources of several 'communities' in this way can also prove more effective in resolving intercommunity conflicts which could otherwise render adaptation untenable (Agrawal \& Gibson, 1999; Chishakwe et al., 2012). Alternative entry points focused on social-ecological systems may also be particularly relevant for Pacific Islanders whose relationships with nature and place influence behaviour (Dacks et al., 2019) and whose livelihoods are significantly dependent upon their surrounding environments (terrestrial and marine) (Nunn et al., 2014).

Several studies also indicate that a focus on effective and legitimate local institutions - based on traditional forms of governance - is critical for activities at the local scale (Chishakwe et al., 2012; Reid, 2016; Galappaththi et al., 2019) and can be a concrete entry point for intervention (Agrawal \& Gibson, 1999). This includes institutions at the 'community' level but also those operating at the ecosystem level and the social or administrative structures in which they lie (Jeans et al., 2014; Galappaththi et al., 2019). Where devolution of authority is ‘institutionally exclusionary’ (i.e. sidelines traditional institutional structures), communitybased efforts can be ineffective and disempowering (Chishakwe et al., 2012: 56). This is because capable local institutions are critical for local decision-making, ensuring active community participation (Reid, 2016) and mediating as well as facilitating particular actions and outcomes (Gibson, 1999; Agrawal \& Gibson, 1999). An institutional focus is relevant for the Pacific, where indigenous designed and operated institutions and governance systems are 
prevalent and can help mobilise resources, better use traditional knowledge and inform or support the management of sustainable adaptation (Nalau et al., 2018, McLeod et al., 2019). Other studies add that it is not just about individual local level institutions but about partnerships and vertical linkages for governance, as higher-level institutions and policies can also shape local-level vulnerability and are critical for securing impact at wider scales (Reid, 2016; Maskrey, 2011; Galappaththi et al., 2019). Alternative entry points should, therefore, encapsulate local institutions that are conducive to developing constructive relationships between national, regional and local domains, and between government and civil society (Maskrey, 2011; Chishakwe et al., 2012). This is especially the case for Small Island Developing States like those in the Pacific where weak linkages between national adaptation efforts and communities or local governments have been identified as key barriers to reducing climate risks (Kuruppu \& Willie, 2015; Piggott-McKellar et al., 2019).

Adapting and working with existing local authority structures for adaptation efforts has also been identified as a key contributor to adaptation success at the local scale (McCarthy, 2014; Remling \& Veitayaki, 2016) and should, therefore, be a key feature within any alternative entry point. Strong local leadership is critical for influencing local decision-making, for supporting the dissemination of information and technologies (Sekine et al., 2009) and fostering ‘community’ participation and ownership over initiatives (Chishakwe et al., 2012; Remling \& Veitayaki, 2016). 'Relations of trust' are critical here: the 'community' must trust the traditional leadership to represent its interests, while the traditional leadership must trust project implementers (Sekine et al., 2009; Chishakwe et al., 2012; Remling \& Veitayaki, 2016). Donor and implementing agencies should, however, avoid the shortcut of selecting prominent members as default leaders and trying to mobilise rural people through them as this could, in effect, establish a power relationship that is open to abuse (Esman \& Uphoff, 
1984; Abraham \& Platteau, 2000). Detailed and extended communication with 'community' members in identifying local agents of change is critical (Platteau, 2004).

Titz et al. (2018) indicate that the haziness of 'community' conceptualisations is problematic as it generates difficulties for unpacking and addressing the root causes of vulnerability and livelihood insecurity. This is concerning given that a conceptual strength of CBA lies in its synergy with development and its 'no-regrets' approach, whereby initiatives look beyond climate risks and seek to improve livelihoods more generally (Heltberg et al., 2009; Barnett \& O’Neill, 2010; McCubbin et al., 2015). Several studies relatedly highlight that steering away from strict adaptation focuses and addressing other non-climatic, shorter-term livelihood pressures at the local scale are important for motivating 'communities' to approve adaptation actions (Chishakwe et al., 2012; Nunn et al., 2014; Ford et al., 2016; Remling \& Veitayaki, 2016). Future work at the 'community' scale and within any alternative entry points, therefore, need to be conducive to understanding and addressing the wider problem context and (non-climatic) root causes of vulnerability. In the Pacific, entry points focused on larger scales to the normative 'community', such as 'whole-of-island' approaches, have previously proved useful for identifying and tackling a range of interrelated challenges (e.g. land and sea-based), which ensued that the adaptation activity resonated with locals (Remling \& Veitayaki, 2016). Multi-scalar assessments are also critical here as the root causes of 'community' vulnerability are often shaped by processes that are external to 'community' geographical boundaries (Barrios, 2014; Kuruppu \& Willie, 2015; Reid, 2016).

A key difficulty with normative 'community' constructs is the assumption of stability, when in reality, 'communities' and social-ecological systems are unbound and in a constant state of emergence and transformation over time (Berkes \& Folke, 1998; Barrios, 2014; Titz et al., 2018). This dynamism should not be overlooked when identifying and working within alternative entry points in the Pacific context as locals have in the past, and continue to, 
experience fundamental transitions as a result of a range of external social, cultural and political pressures (e.g. colonialism, World War II and waves of donor-funded development assistance) (Kuruppu, 2009; Barnett \& Campbell, 2010; Remling \& Veitayaki, 2016). Buggy and McNamara (2016) highlight how the influences of Western worldviews and capitalist systems on traditional governance structures and ways of life have given rise to specific social dynamics, tensions and conflicts within 'communities' that hinder adaptation initiatives. Assessments of context must, therefore, be iterative (Buggy \& McNamara, 2016) and it is critical that alternative entry points to 'community' are less charged with assumptions of stability (Titz et al., 2018).

Others also argue that the unbound nature of 'communities' means we need to put less emphasis on the creation of boundaries (Delanty, 2010) and the sense of 'insiders' and outsiders' (Mulligan, 2015: 347). This is especially true in a world where 'community' constructions are becoming more fluid (Lane \& McDonald, 2005; Mulligan et al., 2016) and can extend to 'virtual', spatially extended networks or 'imagined' communities without contact (Delanty, 2010; Mulligan et al., 2016). People today belong to a range of 'communities' that vary in geographic scale and composition, each fulfilling different needs and interests (Mannarini \& Fedi, 2009; Mulligan et al., 2016) that will also change over time (Agrawal \& Gibson, 1999). The dynamism of boundaries and its members has been observed in the Pacific by Remling and Veitayaki (2016) who illustrate how the scales and boundaries of their 'communities' of focus grew and expanded during the duration of an adaptation project (i.e. people asked to join the projects and ideas/activities naturally diffused into other villages leading to an expansion of the project to the whole island). This reminds us that the ‘community' notion should be reframed as an outcome that can evolve (Oliver-Smith, 2005). We should account for dynamisms and fluidity in boundaries and memberships in any alternative entry points to the geographically bounded 'community'. 
We must avoid adopting idealised notions of 'community' that are simple, undifferentiated and unproblematic in the Pacific (Cannon, 2008) as this can significantly affect the outcomes of community-based initiatives (Lane \& McDonald, 2005; Buggy \& McNamara, 2016). Unique political and social dynamics and contexts must be critically analysed to give rise to contextually appropriate alternative entry points that go beyond normative 'community' constructs. It is these alternative entry points that we explore in the context of Vanuatu below.

\section{Methods}

This study utilised a field-based qualitative research approach and involved three core case studies: 1) Lorevuilko village in Espiritu Santo, 2) Pele Island and 3) central and ring road marketplaces (Figure 1). The diverse sites chosen represent various points along a coreperiphery gradient: from the capital of Port Vila to villages in Efate and islands off Efate, to the more remote Espiritu Santo. The selection of sites was based on the research team's networks in Vanuatu as this was considered the most appropriate way to gain trusted access to communities and all data was collected during November-December 2018.

Focus groups were the primary method used in each of the case study sites to explore the multiple experiences and perceptions of people in relation to local adaptation initiatives. The choice in using focus groups was driven by a need for participants to own the discussion spaces so that richer, more complex and deeper dialogue could unfold (Leavey, 2014; Kamberelis \& Dimitriadis, 2013). Additionally, focus groups were deemed a culturally sensitive method for our study as the processes of 'collective talk' and shared dialogue are appropriate for communitarian indigenous cultures (Madriz, 2003) like those in the Pacific. The focus groups were generally split according to gender (and at times, age) where possible to help reduce the impact of entrenched power structures (Leavey, 2014). 
A small number of semi-structured interviews and informal conversations were also undertaken with community members in two of the case studies sites (Espiritu Santo and Pele Island). Although not as conducive to extensive collective participant knowledge sharing and exchange, semi-structured and informal approaches with individuals and smaller groups are highly beneficial in, and compatible to, the Pacific Islands context (Warrick, 2009; Vaioleti, 2006).

In Lorevuilko on Espiritu Santo (Figure 1), the researchers engaged students from the technical college and members of the Anglican mission in focus group discussions, formal interviews and informal conversations. One focus group was undertaken with local women ( $n=15$ participants), one with local men ( $n=8$ participants) and one with students $(n=3$ participants). This was coupled with three semi-structured interviews with the Acting Principal of the college, the Minister of the Anglican Church, and a key informant who assisted in the implementation of adaptation projects (all men). The total participants were 29 (18 women, 11 men). In Piliura and Woreau on Pele Island (Figure 1), the researchers undertook two focus groups with men ( $\mathrm{n}=8$ participants) and one with women $(\mathrm{n}=3$ participants), along with two semi-structured interviews (one woman, one man) and several informal discussions during the visit. The total participants on Pele Island were 13 (nine men, four women).

On both Espiritu Santo and Pele, the same gatekeeper, participant recruitment strategy and focus group guide were used. The gatekeeper was a key person in the researcher's climate change network in Vanuatu and had been involved in the implementation of adaptation projects in these sites. The gatekeeper was critical for providing introductions, inviting participants to be involved in this study and providing translations during the focus groups when required. Focus group guides (see Hennink, 2014) were used to assist in the flow of discussions. Several key elements were included in the structure: introductions and 
participant consent, icebreakers to help foster rapport, questions around livelihood threats, experiences of environmental changes/events and adaptation responses (both local and external projects), and questions relevant to how externally implemented CBA responses performed in terms of appropriateness, effectiveness, equity, impact and sustainability. For the study focused on central and ring road marketplaces, a series of focus groups $(n=10)$ were conducted in December 2018. This involved 55 market vendors (53 women and 2 men), who were all involved in the UN-Women's 'Markets for Change' program. Most participants were women because, in Vanuatu and the Pacific more generally, marketplaces are sites where women are central (Barnett-Naghshineh, 2019; Busse \& Sharp, 2019), with women making up seventy-five to ninety percent of marketplace operations such as vending (Pacific Islands Forum Secretariat, 2013). Participants included those from larger, central marketplaces in Vanuatu such as the Port Vila central marketplace $(n=11)$, the Port Vila handicraft marketplace $(n=3)$ and Marobe marketplace $(n=6)$ (Figure 1). Some vendors interviewed at these central marketplaces were from islands just north of Efate (Nguna $(n=2))$ or even further north (e.g. Emae, Tongariki and Epi) but had travelled to sell their products. Participants from ring road marketplaces included those selling at Paunangisu $(n=4)$, Epule $(n=5)$, Epao $(n=6)$ and Emua $(n=8)$ on Efate (Figure 1). The remaining participants were from the Silae Vanua Market Vendor Association (SVMVA) executive team ( $\mathrm{n}=7)$ in Efate or vendors from the Luganville marketplace in Espiritu Santo $(n=3)$ (Figure 1). A focus group guide was used and included the following elements: brief discussion of participant's backgrounds; history and production of marketplaces; benefits and challenges of marketplaces; and impacts of climate change and disasters on production and livelihoods. Instantaneous translations during the focus groups were provided by a local ni-Vanuatu research assistant. 
All focus groups and interviews were digitally recorded and later transcribed verbatim. From here, latent content analysis was conducted using NVivo. Latent content analysis is an interpretive technique used to code social data for both surface and underlying meanings of discussions, allowing findings to be more than just exact words spoken but also not diverging too far from original text (Bengtsson, 2016). The essence of discussions was ascertained and represented as 'themes', which are detailed in this paper. Ethics approval for this project was granted through the University of [withheld for peer review] Ethics Sub-committee (approval number [withheld for peer review]) and a research permit was granted through the Vanuatu Cultural Centre.

\section{Alternative entry points to 'community' for adaptation}

\section{Technical colleges: sites for learning, innovation and dissemination}

Rural training centres in Vanuatu are common, providing vocational skills to ni-Vanuatu in fields including agriculture, hospitality and automotive. One of these rural training centres (also known locally as a technical college), in the north of the country, is operated and financed by the Anglican Church and embedded within the Anglican Church mission. The village of families and students within this Anglican mission is comprised of approximately 200 members, with the students travelling from across the country to attend the technical college and pay tuition fees. Land, which the mission currently informally leases from the local Chief (who is three families strong), will soon be formalised. Life is largely subsistent with food grown predominately for consumption, albeit surplus produce is bound for the local marketplaces. Some village members work on copra or forest plantations or on livestock farms owned by other local villages or corporate entities. As freshwater access is limited and there is no nearby natural running source, water is largely harvested from the roofs of houses, the church, the technical college, and the primary school. During the dry season, when the freshwater runs dry, community members walk $15 \mathrm{~km}$ to collect water from other sources: "I 
was always trying hard to catch water... there is no source of water, all the water is all dried up, we have to walk for the water, far" (Acting Principal, 2018).

In 2017, the technical college - embedded within this Anglican mission village - hosted an adaptation project that involved a series of demonstration initiatives largely addressing food and water security. Specifically, the adaptation initiatives focused on 1) the protection of harvested water from pollution and insect-borne diseases through appropriate covering, 2) the establishment of a chicken coop and provision of training in chicken rearing for meat, and 3) the creation of a fish farm demonstration site and the provision of fish farming training. These initiatives, which are discussed in more detail below, were placed within the remit of the technical college, while the ownership of the project rests with the government that is responsible for curriculum accreditation. The success of this project in varying ways demonstrates how technical colleges may be appropriate and effective entry points for adaptation that go beyond normative 'community' conceptualisations.

The goal of the first adaptation initiative was to safely store and secure water near the training college. This involved restoring a well that previously stored rainwater runoff from the Church, but had since been used for rubbish disposal. Restoration was relatively straightforward with only minimal resources needed for cleaning as well as building the covering and structure to protect the stored water:

“...put the cover and net around it - that's the one where people had forgotten about it - they throw stone inside, rubbish... it helped us a lot as the well always fill up every time the rain came and it is protected so there's no rubbish in it, so we just use it and no mosquito" (Acting Principal, 2018).

This initiative was simple yet very effective, and a significant portion of its sustained success could be attributed to the unique management through the technical college that had few 
internal disputes and was only located a few metres away. Staff at the technical college continue to ensure that the storage unit does not revert to being used for waste disposal and there are regular checks to ensure that the covering does not need repairs.

For the other two initiatives - chicken rearing and fish farming - there were some success, lessons learned and exciting prospects to be incorporated into future demonstration sites. For the fish farms, for example, participants had a strong desire to re-implement the initiative and integrate core-learnings (e.g. splitting female and male fish to avoid over-breeding and implementing fencing to mitigate theft). Although both initiatives were undertaken as food security initiatives, they also both became a source of income for the college and a useful training and learning exercise. In terms of the latter, it became clear that benefits were being transferred beyond the initial site itself as students took their learnt knowledge and skills back to their home villages once they completed their studies. The Acting Principal indicated how one former student went home to his village and mimicked the fish ponds (using plastic sheeting in a big hole in the ground compared with the cement tanks that were built at the college), thereby providing his own family with a source of income and subsistence. The importance of knowledge and skill transfers in this way was summed by one participant:

"It's good to not just have the agricultural students [with the farming knowledge for example], share some of that knowledge - it should be shared to everyone, regardless of whichever [field they are in]... because it's a livelihood, when they go back to their various communities, they can learn, because this is not just for money, it is for subsistence use in their communities, it's a livelihood avenue" (Key informant, 2018).

Apart from the automatic mechanism for knowledge and skill transfers beyond those directly involved, another key benefit of using a technical college as a local entry point was the existence of strong and stable governance structures. By utilising existing structures, project implementers were able to secure effective management over, and ongoing commitment to, 
the adaptation project. According to a key informant, "governance at a community level is complex in Vanuatu, many communities have multiple and competing claims as to who is the chief and internal conflict and power dynamics" (Key informant, 2018). This site was chosen because of the community cohesion and lack of internal Kastom - broadly meaning 'custom' and 'tradition' - disputes. Such a dynamic was possible given the central role of the Anglican mission and the characteristics of participants who are all migrants from other parts of Vanuatu.

Whole-of-island approach: crown-of-thorn starfish eradication initiative

In 2010-2011, there was an outbreak of the crown-of-thorns (COT) starfish on important food-producing reefs and associated nearshore ecosystems on Pele Island, Vanuatu. Pele Island, located 7 kilometres off the north Coast of Efate Island, covers a land area of 4.3 square kilometres and supports a total population of 400 members who are spread across four villages on the island. These villages are well-connected through kinship relationships. The major ways in which these largely self-sufficient communities maintain their livelihoods is through fishing, tourism, small-scale agriculture and remittance from family members working in either Port Vila or overseas.

The COT outbreak significantly affected the community's vulnerability by damaging the marine resources on which their livelihoods depend: the "...reef is important for fishing and tourism" (Woreau village focus group, 2018). In discussions with community members, it became clear that participants were aware of the outbreak but, having never experienced it before, lacked the knowledge for effective management. In 2013, a development partner, who was working in Pele Island on various adaptation initiatives, supported and trained the community members in effective management strategies. This involved training in the collection, appropriate handling (i.e. to not spread eggs), land-based killing, and composting of the COT starfish carcasses. 
The initiative outcomes were positive with the successful containment of the outbreak. No further outbreaks have occurred up until the research was conducted in late 2018. A large contributing factor to its successful operation was the various incentivising strategies (e.g. clean-up competitions involving prizes), as these strategies effectively motivated the local population to participate in the COT management process. Another important factor for the success of the project was its focus on the problem context and its whole-of-island approach which was perceived as extremely equitable, involving everyone: "all man, all women, all picinini [children]" (Piliura village focus group, 2018).

Discussions highlighted the need to pass down to future generations the knowledge on how to manage COT outbreaks. When asked about the project's sustainability, one participant highlighted the longevity as an ecosystem-based adaptation approach: "We think it's great...we see the results and know it's our responsibility" (Woreau village focus group, 2018). When questioned whether the community would need outside support again should the problem re-emerge, another community member explained: “We know our resources are the water, if the coral is dead there is no more fish, so we will collect and prevent, and we know how... so the Chief or conservation committee will encourage people to go out and collect starfish" (Piliura village focus group, 2018). This approach was perceived as highly appropriate, equitable and sustainable, and was praised for having the impact desired by local populations. The success of this project also demonstrates how utilising the problem context (i.e. an acute environmental problem) and larger scales than the normative 'community' may be credible and effective entry points for adaptation.

\section{Marketplaces: sites for enhanced adaptive capacity}

Marketplaces and their 'collective of vendors' may also be effective entry points for adaptation. Typical products sold by these women at the marketplace involved fruits, vegetables, nuts and jam, as well as handicraft products such as painted clothing, baskets, 
fans and hats. Women vendors spend a large portion of their time participating in activities related to the marketplace, and this involves gardening, preparing products, packaging, transporting and then selling. Some vendors travel long distance to sell products (i.e. interisland), which can involve sleeping for days or weeks at a time at the marketplace. Cyclones have been a particular threat to the marketplace and its vendors' livelihoods by destroying critical infrastructure and the gardens from which products are derived. There are two main reasons for putting forward marketplaces and their collectives of vendors as effective entry points for adaptation: the first is the extensive social networks among women vendors that result in diverse and multiple positive outcomes, and the second is the well-established governance system that brings voices and collective action to the fore. These key reasons are discussed in more detail below.

Women market vendors work together, and in times of crisis, this is particularly pertinent. The women vendors explained how their social networks extended across islands and how they have been fostered and strengthened by the interactive nature of marketplaces: "We don't know each other because we are in different villages, but then we come over to the marketplace and then we started to talk together and we start sharing" (Marobe focus group, 2018). These extensive networks have been a critical resource that can be drawn upon in times of stress (e.g. produce shortages). In the face of Cyclone Pam, for example, social networks acted as safety nets for women when they were temporarily low on stock for various reasons:

"She make orders to other islands, to other women. So family members that are in Palma or Ambrym that have nuts, or Epi... they send it over to her and then she resells it and gets her money, but she pays them... oh they do exchange with food. They package them a box of food for that muma and that muma sends things over" (Nguna women/Central market, 2018). 
These social networks are also critical for ensuring equity and inclusiveness in disaster recovery and adaptation as they consistently support those less abled (i.e. widows, disabled women) or those burdened by workloads and peripherality to recover following major events. For example, many women vendors who were badly affected by Cyclone Pam were able to maintain post-disaster income streams as other more-abled women would travel to marketplaces and sell their products for them.

Women's social networks encapsulated within the marketplace scale are also critical for supporting the transfer of knowledge, ideas and skills beyond one household, 'community' and island. This was demonstrated in the women's sharing of income diversification strategies and skills. As women vendors better recognised the risk of depending on climatesensitive income streams, some diversified their livelihoods with the support of training provided by external agencies. Diversification activities involved either selling a wider range of products at marketplaces or using savings and loans to springboard into other livelihood activities (e.g. guesthouses, canteens, handicrafts, t-shirt printing, poultry, jam-making, sewing and weaving). These diversification strategies and skills were shared across women's social networks: "Having other information from other women, how they're actually earning money, she's doing [it] now [too]... she's doing other things to gain money" (Emua market focus group, 2018). This means that women market vendors are teaching and exposing others in their networks to ways that develop financial resilience, boost adaptive capacity and prepare for a hopeful future. This local scale entry point, therefore, has an automatic mechanism for enhancing the adaptive capacities and resilience of a larger population.

This transfer of knowledge, ideas and skills is further supported by the transient nature of marketplaces. It is common for vendors who travel from afar (e.g. other islands) to sell at the marketplaces to implement and further share their acquired knowledge, skills and ideas when they return home: "They are doing printing, painting and all this stuff just for money before 
they came back to their communities and they do the same thing as well" (SVMVA executive team focus group, 2018). While marketplaces and vendors offer an entry point for adaptation at a local scale, they also act as bridges across multiple communities and households and, by virtue, have a multiplier effect that can heighten the reach of adaptation interventions.

The marketplaces also have a well-established governance system that is conducive to bringing marginal voices to the fore, collective action and strengthening relationships with local authorities. Most market vendors are part of smaller marketplace associations that fall under an umbrella Association (SVMVA). The umbrella Association functions through a series of monthly general meetings where vendors at different marketplaces across Efate can make specific requests and express concerns to the executive team. The executive team is then responsible for finding avenues to meet needs. This structure is a key strength of this local institution as it ensures that local representatives from numerous marketplaces have equitable representation and a platform to voice concerns. As one participant who travels from a small island north of Efate to sell at central marketplaces stated, "it's an avenue that they can come through to raise concerns... They think this is the way forward to address their issues" (Nguna women/Central market, 2018). Concerns raised are directly (e.g. table fees) but also indirectly (e.g. road conditions) related to marketplaces.

The marketplace associations have also acted as a foundation from which women can convene and lobby for their rights and needs or voice their concerns to external institutions. For example, following Cyclone Pam, groups of women associated with marketplace associations lobbied against local governments and aid agencies who they perceived as sidelining their priorities and participation in the distribution of aid relief. Through a good relationship with a local chief and local government representatives, the umbrella Association has also supported women's abilities to voice concerns to local authorities, pursue sponsors for projects and negotiate by-laws that give them more rights. The marketplace also enables 
improved flows of information across scales: “...communication and information passes down [from the local government] all the way to the women, so the women are well informed about what's happening at the province level" (Emua market focus group, 2018). These inherent strengths render local marketplaces and the 'collective of vendors' effective entry points which would support adaptation projects to have a wider reach and larger impact.

\section{Discussion}

The three distinct alternative entry points - which all still occur at a local scale - offer insights and opportunities that may help overcome ongoing and inherent issues with the normative 'community' notion in CBA. Some of these insights and learnings are unique to each case, while others have common threads.

The rural technical college, as an entry point for adaptation, is unique. Focusing on a rural technical college embedded within an Anglican mission allowed the project to overcome common problems associated with assumptions of 'community' harmony. By having an entry point characterised by members of one religious domination, this intervention avoided the problematic and complex local power dynamics that can arise from traditional 'communities' that cut across multiple religions and denominations (see Kuruppu, 2009; Clissold \& McNamara, 2019). This also meant that Kastom disputes - where the complexities of sociopolitical context and local interests becomes a constraining factor (Agrawal \& Gibson, 1999; Buggy \& McNamara, 2016) - could be minimised through this entry point. Although the rural technical college is Anglican and within the mission, the core ownership of the project rests with, and is accredited through, the technical authority, which meant that there was also a pre-existing overseeing local authority that could keep any internal disputes to a minimum.

Centering these initiatives in the remit of the technical college was also appropriate, effective and sustainable as it ensured that, once project funding has ceased, the project could continue 
to operate (e.g. pilot demonstration initiatives (chicken rearing and fish farms) could be started again by college staff). Given the success of chicken rearing and fish farms as demonstration initiatives for training and learning purposes, the college plans to implement the demonstration initiatives again for future student cohorts.

The success of the whole-of-island approach can be found on several levels. The COT management approach was not defined by a traditional 'community' boundary but rather by the social-ecological system in which the problem was situated (Berkes \& Folke, 1998; Berkes et al., 2003). This alternative entry point allowed for identification and tackling of seascape issues that resonated with islanders in diverse ways (Remling \& Veitayaki, 2016). Rather than a focus on one territorially fixed and exclusive 'community', focusing on the social-ecological problem context helped transcend boundaries and ensured that all people with diverse concerns, livelihoods and uses of the ecosystem (e.g. fishing or tourism) were involved and equally benefit. In this way, the project traversed gender and age barriers, which often exist in adaptation projects, to eliminate risks of exclusion and emphasise a shared responsibility. This alternative entry point may be particularly relevant in other rural Pacific islands where there are complex and critical relationships and dependencies between people, nature and place (Nunn et al., 2014; Remling \& Veitayaki, 2016; Dacks et al., 2019). The divergence from small, territorially fixed boundaries was also particularly important in this context as participants later shared that the two participating villages on the island were loosely defined and had fluid boundaries with families and kinship relations spread across both. Alternative entry points such as those focused on larger scales (e.g. socio-ecological systems and whole islands) are, therefore, also appropriate and critical for their conduciveness to the unbound nature of local populations and their networks/kinship systems in certain contexts. 
Importantly, the whole-of-island approach was not in response to a problem context concocted by an external entity, where problems and/or solutions are often borne from the implementing agency (Westoby et al., 2019). In this case, local people identified the problem context necessitating a solution. While the COT starfish management program was based on the implementer's technical knowledge, they also successfully used incentives, in the form of short-term, tangible benefits to encourage local people to 'own' the action (Chishakwe et al., 2012; Nunn et al., 2014; Reid, 2016; Remling \& Veitayaki, 2016). The project was sustainable because local people could see the success of their work, and therefore did not fall into the trap of other adaptation projects that often fail due to lost momentum, finance or maintenance problems (Buggy \& McNamara, 2016; Westoby et al., 2019).

One common and compelling attribute that binds all three alternatives was the importance of fluid boundaries that are not closed but open to anyone, thereby being less charged by assumptions of stability. The scale and boundaries of these entry points can, unlike the normative concept of 'community', expand and evolve (Remling \& Veitayaki, 2016; OliverSmith, 2005), thereby having a multiplier effect. Both the rural technical college and marketplaces, for example, are transient spaces (e.g. vendors travel from afar to sell and migrant students also graduate and leave) and encapsulate social networks that transcend one household, village or even island. Fluid boundaries support extensive benefit, idea and skill transfers that enhance the adaptive capacity and resilience of a larger population, thereby having a wider impact than normative, fixed 'community' notions. In this way, the marketplace and rural technical college are alternatives that act as demonstration and pilot sites for the introduction of new ideas and practices. From these demonstration sites, the reach of adaptation automatically expands as ideas and knowledge diffuse through social networks into other households, villages and islands (see also Remling \& Veitayaki, 2016). This gives rise to a key lesson: implementers should consider 'alternative' entry points that 
are fluid, open and conducive to transient members and benefit transfers beyond any strict, fixed geographical boundary. Less focus on 'boundaries' and which members may be 'insiders' or 'outsiders' will, after all, become increasingly important as 'communities' inevitably become more fluid (Mannarini \& Fedi, 2009; Mulligan et al., 2016). The whole-ofisland approach also illustrated the importance of fluid boundaries by focusing on a problem context that was beyond one 'community'; it was a wider social-ecological problem that required an integrated, wider scale approach.

Another common attribute is that all the alternative entry points are conducive to understanding and addressing non-climatic root causes of vulnerability. All the projects channelled through alternative entry points considered other underlying stressors, beyond climate risks, that help improve livelihoods more generally (Barnett \& O’Neill, 2010; McCubbin et al., 2015). The whole-of-island approach was a livelihood protection initiative, while the marketplaces and rural technical college focused on livelihood diversification. By producing tangible, immediate livelihood benefits, these initiatives were well received by local people and provided the appropriate incentives to motivate sustainable adaptation (see Chishakwe et al., 2012; Nunn et al., 2014; Remling \& Veitayaki, 2015).

Finally, all alternatives utilised effective and legitimate local institutions based on traditional forms of governance which was key to their success (Chishakwe et al., 2012; McCarthy, 2014; Reid, 2016). The whole-of-island approach based on a social-ecological system utilised the conservation committee and Kastom approaches as traditional governance structures that would ensure momentum and sustainable COT management activities beyond the project lifetimes (i.e. when funding ceases). Understanding and working with existing institutions operating at the ecosystem scale has previously been highlighted as critical for ensuring adaptation initiatives are effective (Jeans et al., 2014). The strong governance structure of the rural technical college was also a concrete local government institution, which increased the 
likely maintenance of the initiatives. The federated structure of the SVMVA in the marketplaces, with local representatives from other smaller marketplace associations, is another example of local institutional strength that can be used as an entry point for adaptation. This structure effectively helps mobilise resources towards particular outcomes, represents and considers the marginal voices of smaller marketplaces, and provides the capital from which vendors can draw on to fight for their rights; all elements of a strong, legitimate institution necessary for sustainable and effective adaptation (Agrawal \& Gibson, 1999; Nalau et al., 2018; McLeod et al., 2019). Another related and compelling factor for using existing marketplace institutions as an alternative entry point to the 'community' is its already well-established relationships with local authorities and higher governments (Maskrey, 2011; Chishakwe et al., 2012). This has meant that multi-scalar factors that are contributing to the local vulnerability of market vendors can be addressed (e.g. by negotiating by-laws for more rights as market vendors) (Reid, 2016; Maskrey, 2011). By using a local institution as an entry point for adaptation, we can take advantage of, and work with, existing capacities and strengths more effectively, and we are also incentivised to better understand local-level processes rather than make assumptions (Agrawal \& Gibson, 1999).

\section{Conclusion}

With community-based initiatives under-performing and criticisms increasingly emerging around the normative notion of 'community', future CBA initiatives would benefit from considering more creative and alternative entry points for interventions. We explored three alternatives in Vanuatu: adaptation demonstrations embedded into a rural technical college; a whole-of-island approach to COT starfish management, and marketplaces as sites for enhancing adaptive capacity for women vendors. From these cases, we offer compelling and valid entry points that are less charged with problematic assumptions. These alternatives are couched in fluid community boundaries and are not defined by traditional spatial structures 
based on geography. They are development-focused and support the diversification and/or protection of livelihoods, thereby producing tangible and immediate benefits that can enhance the sustainability of adaptation efforts. They also build on local and legitimate institutions, which are the bedrock for sustainability. While only a start, these alternative entry points offer hope and provide ways that we can expand on and complement restricted notions of 'community' in adaptation, thereby improving adaptation outcomes in the future. We hope to stimulate the exploration of and debate around more spatially and temporally creative alternatives to traditional community-based initiatives in Vanuatu and beyond.

\section{Acknowledgements}

We are grateful to the participants for providing valuable and meaningful insights in this study. We also wish to thank our local research assistants who were instrumental in organising fieldwork logistics and providing translation. This research was funded through an Australian Research Council Linkage grant (number [withheld for peer review]).

\section{Reference list}

Abraham, A. \& Platteau, J-P. (2000). The central dilemma of decentralized rural development. Paper presented at the Conference on New Institutional Theory, Institutional Reform, and Poverty Reduction. London School of Economics, London. 7-8 Sept 2000. Agrawal, A. (1999) Greener Pastures: Politics, Markets, and Community among a Migrant Pastoral People. Durham, NC: Duke University Press.

Agrawal, A., \& Gibson, C. C. (1999). Enchantment and Disenchantment: The Role of Community in Natural Resource Conservation. World Development, 27(4), 629-649. https://doi.org/10.1016/S0305-750X(98)00161-2 Australian National University (ANU), 2018a. Vanuatu. Retrieved from http://asiapacific. anu.edu.au/mapsonline/base-maps/vanuatu-0. 
Australian National University (ANU), 2018b. Efate, Vanuatu. Retrieved from https:// asiapacific.anu.edu.au/mapsonline/base-maps/efate-vanuatu-0.

Barnett, J., \& Campbell, J. (2010). Climate change and small island states: Power, knowledge and the South Pacific. London and Washington, DC: Earthscan.

Barnett, J \& O’Neill, S 2010, ‘Maladaptation', Global Environmental Change, vol.20, no. 2, pp. 211-213. https://doi.org/10.1016/j.gloenvcha.2009.11.004

Barnett-Naghshineh, O. (2019). Shame and Care: Masculinities in the Goroka Marketplace. Oceania, 89(2), 220-236. https://doi.org/10.1002/ocea.5219

Barrios, R. E. (2014). 'Here, I'm not at ease': Anthropological perspectives on community resilience. Disasters, 38(2), 329-350. https://doi.org/10.1111/disa.12044

Bengtsson, M. (2016). How to plan and perform a qualitative study using content analysis. NursingPlus Open, 2, 8-14. https://doi.org/10.1016/j.npls.2016.01.001

Berkes, F., Colding, J., \& Folke, C. (2003). Navigating social-ecological systems: building resilience for complexity and change. New York: Cambridge University Press.

Berkes, F., \& Folke, C. (1998). Linking Social and Ecological Systems: Management Practices and Social Mechanisms for Building Resilience. New York: Cambridge University Press.

Boyd, E., Grist, N., Juhola, S., \& Nelson, V. (2009). Exploring Development Futures in a Changing Climate: Frontiers for Development Policy and Practice. Development Policy Review, 27(6), 659-674. https://doi.org/10.1111/j.1467-7679.2009.00464.x

Buggy, L., \& McNamara, K. E. (2016). The need to reinterpret "community" for climate change adaptation: A case study of Pele Island, Vanuatu. Climate and Development, 8(3), 270-280. https://doi.org/10.1080/17565529.2015.1041445 
Busse, M., \& Sharp, T. L. M. (2019). Marketplaces and Morality in Papua New Guinea: Place, Personhood and Exchange. Oceania, 89(2), 126-153.

https://doi.org/10.1002/ocea.5218

Cannon, T. (2008). Reducing People's Vulnerability to Natural Hazards (WIDER Research Paper No. 2008/34). The United Nations University World Institute for Development Economics Research (UNU-WIDER).

Chishakwe, N., Murray, L., Chambwera, M., \& International Institute for Environment and Development. (2012). Building climate change adaptation on community experiences:

Lessons from community-based natural resource management in southern Africa. http://pubs.iied.org/pdfs/10030IIED.pdf

Clarke, T., K.E. McNamara, R. Clissold, and P.D. Nunn. 2019. Community-based adaptation to climate change: Lessons from Tanna Island, Vanuatu. Island Studies, 14(1), 59-80. https://doi.org/10.24043/isj.80

Clissold, R., \& McNamara, K. E. (2019). Exploring local perspectives on the performance of a community-based adaptation project on Aniwa, Vanuatu. Climate and Development, 1-12. https://doi.org/10.1080/17565529.2019.1640656

Dacks, R., Ticktin, T., Mawyer, A., Caillon, S., Claudet, J., Fabre, P., Jupiter, S. D., McCarter, J., Mejia, M., Pascua, P., Sterling, E., \& Wongbusarakum, S. (2019). Developing biocultural indicators for resource management. Conservation Science and Practice, 1(6), e38. https://doi.org/10.1111/csp2.38

de Beer, F. (2013). Community-based natural resource management: Living with Alice in Wonderland? Community Development Journal, 48(4), 555-570. https://doi.org/10.1093/cdj/bss058

Delanty, G. (2010). Community, 2nd edn. London: Routledge. 
Ensor, J. 2016. Resilience realities: Resilience and development practice in Vanuatu, Oxfam, Vanuatu. http://eprints.whiterose.ac.uk/124325/1/Resilience_Report_Web_2_.pdf. Accessed 19 May 2020.

Esman, M. J., \& Uphoff, N. T. (1984). Local Organisations: Intermediaries in Rural Development. Cornell University Press.

Ford, J.D., Stephenson, E., Cunsolo Willox, A., Edge, V., Farahbakhsh, K., Furgal, C., Harper, S., Chatwood, S., Mauro, I., Pearce, T., Austin, T., Bunce, A., Bussalleu, A., Diaz, J., Finner, K., Gordon, A., Huet, C., Kitching, K., Lardeau, M-P., McDowell, G., McDonald, E., Nakoneczny, L., \& Sherman, M. (2016). Community-based adaptation research in the Canadian Arctic. WIREs Clim Change, 7, 175-191. https://doi.org/10.1002/wcc.376 Galappaththi, E.K., Ford, J.D., Bennett, E.M. \& Berkes, F. (2019). Climate change and community fisheries in the arctic: A case study from Pangnirtung, Canada. Journal of Environmental Management, 250, 109534. https://doi.org/10.1016/j.jenvman.2019.109534 Gibson, C. (1999) Politicians and Poachers: The Political Economy of Wildlife Policy in Africa. Cambridge: Cambridge University Press.

Girot, P., Ehrhart, C., Oglethorpe, J., Reid, H., Rossing, T., Gambarelli, G.,... Phillips, J. (2012). Integrating community and ecosystem-based approaches in climate change adaptation responses. Ecosystems \& Livelihoods Adaptation Network. https://d2ouvy59p0dg6k.cloudfront.net/downloads/integrating_community_and_ecosystem_b ased_approaches_in_climate_change_adaptation_res.pdf. Accessed 16 May 2020 . Hay, J., \& Mimura, N. (2013). Vulnerability, risk and adaptation assessment methods in the Pacific Islands region: past approaches, and considerations for the future. Sustain. Sci, 8, 391405. https://doi.org/10.1007/s11625-013-0211-y 
Heltberg, R., Bennett Siegel, P., \& Jorgensen, S.L. (2009). Addressing human vulnerability to climate change: Toward a "no-regrets" approach. Global Environmental Change, 19(1), 8999. https://doi.org/10.1016/j.gloenvcha.2009.11.003

Hennink, M.M. (2014). Focus group discussions. New York: Oxford University Press. Hudson, K.D. (2012). Bordering Community: Reclaiming Ambiguity as a Transgressive Landscape of Knowledge. Journal of Women and Social Work,27(2), 167-179.

Intergovernmental Panel on Climate Change (2014). Climate Change 2014: Impacts, Adaptation, and Vulnerability. Part A: Global and Sectoral Aspects. Contribution of Working Group II to the Fifth Assessment Report of the Intergovernmental Panel on Climate Change. C.B. Field, V.R. Barros, D.J. Dokken, J.K. Mach, M.D. Mastrandrea, T.E. Bilir, M. Chatterjee, K.L. Ebi, Y.O. Estrada, R.C. Genova, B. Girma, E.S. Kissel, A.N. Levy, S. MacCracken, P.R. Mastrandrea, and L.L. White, eds. (Cambridge University Press). Jeans, H., Oglethorpe, J., Phillips, J., \& Reid, H. (2014). The role of ecosystems in climate change adaptation: Lessons for scaling up. In E.L.F. Schipper, J. Ayers, H. Reid, S. Huq \& A. Rahman (Eds.), Community based adaptation to climate change: scaling it up (pp. 253-265). London: Routledge.

Kamberelis, G. \& Dimitriadis, G. (2013). Focus groups from structured interviews to collective conversations. London and New York: Routledge.

Kuruppu, N. (2009). Adapting water resources to climate change in Kiribati: The importance of cultural values and meanings. Environmental Science \& Policy, 12(7), 799-809. https://doi.org/10.1016/j.envsci.2009.07.005

Kuruppu, N., \& Willie, R. (2015). Barriers to reducing climate enhanced disaster risks in Least Developed Country-Small Islands through anticipatory adaptation. Weather and Climate Extremes, 7, 72-83. https://doi.org/10.1016/j.wace.2014.06.001 
Lane, M. B., \& McDonald, G. (2005). Community-based Environmental Planning:

Operational Dilemmas, Planning Principles and Possible Remedies. Journal of

Environmental Planning and Management, 48(5), 709-731.

https://doi.org/10.1080/09640560500182985

Leavey, P. (2014). Oxford Handbook of Qualitative Research. New York: Oxford University Press.

Luetz, J. M., \& Nunn, P. (2020). Climate Change Adaptation in the Pacific Islands: A Review of Faith-Engaged Approaches and Opportunities. In W. L. Filho (Ed.), Managing Climate Change Adaptation in the Pacific Region (pp. 293-312). Springer Nature.

Madriz, E. (2003). Focus groups in feminist research. In N.K. Denzin \& Y.S. Lincoln (Eds.), Collecting and interpreting qualitative materials (3 ${ }^{\text {rd }}$ ed.) (pp. 375-402). Thousand Oaks, CA: Sage.

Mannarini, T., \& Fedi, A. (2009). Multiple senses of community: The experience and meaning of community. Journal of Community Psychology, 37(2), 211-227.

https://doi.org/10.1002/jcop.20289

Maskrey, A. (2011). Revisiting community-based disaster risk management. Environmental Hazards, 10(1), 42-52. https://doi.org/10.3763/ehaz.2011.0005

McCarthy, J. F. (2014). Using community led development approaches to address vulnerability after disaster: Caught in a sad romance. Global Environmental Change, 27, 144-155. https://doi.org/10.1016/j.gloenvcha.2014.05.004

McCubbin, S., Smit, B., \& Pearce, T. (2015). Where does climate fit? Vulnerability to climate change in the context of multiple stressors in Funafuti, Tuvalu. Global Environmental Change, 30, 43-55. https://doi.org/10.1016/j.gloenvcha.2014.10.007 
McLeod, E., Burton-Adams, M., Förster, J., Franco, C., Gaines, G., Gorong, B., James, R., Posing-Kulwaum, G., Tara, M. \& Terk, E. (2019). Lessons from the Pacific Islands Adapting to Climate Change by Supporting Social and Ecological Resilience. Frontiers in Marine Science, 6, 289. https://doi.org/10.3389/fmars.2019.00289

McNamara, K.E. (2013). Taking stock of community-based climate-change adaptation projects in the Pacific. Asia Pacific Viewpoint, 54, 398-405. https://doi.org/10.1111/apv.12033

McNamara, K.E., Clissold, R., Westoby, R., Piggott-McKellar, A.E., Kumar, R., Clarke, T., Namoumou, F., Areki, F., Joseph, E., Warrick, O., \& Nunn, P. (2020). An assessment of community-based adaptation initiatives in the Pacific Islands, Nature Climate Change, 10, 628-639. https://doi.org/10.1038/s41558-020-0813-1

Mulligan, M. (2015). On Ambivalence and Hope in the Restless Search for Community: How to Work with the Idea of Community in the Global Age. Sociology, 49(2), 340-355. https://doi.org/10.1177/0038038514534008 Mulligan, M., Steele, W., Rickards, L., \& Fünfgeld, H. (2016). Keywords in planning: What do we mean by 'community resilience'? International Planning Studies, 21(4), 348-361. https://doi.org/10.1080/13563475.2016.1155974

Nalau, J., Becken, S., Schliephack, J., Parsons, M., Brown, C., \& Mackey, B. (2018). The Role of Indigenous and Traditional Knowledge in Ecosystem-Based Adaptation: A Review of the Literature and Case Studies from the Pacific Islands. Weather, Climate, and Society, 10(4), 851-865. https://doi.org/10.1175/WCAS-D-18-0032.1

Narayan, S., Esteban, M., Albert, S., Jamero, M. L., Crichton, R., Heck, N., Goby, G., \& Jupiter, S. (2020). Local adaptation responses to coastal hazards in small island communities: 
Insights from 4 Pacific nations. Environmental Science and Policy, 104, 199-207.

https://doi.org/10.1016/j.envsci.2019.11.006

Nunn, P. D., Aalbersberg, W., Lata, S., \& Gwilliam, M. (2014). Beyond the core:

Community governance for climate-change adaptation in peripheral parts of Pacific Island Countries. Regional Environmental Change, 14(1), 221-235. https://doi.org/10.1007/s10113013-0486-7

Nunn, P., \& Kumar, R. (2019). Cashless Adaptation to Climate Change: Unwelcome yet Unavoidable? One Earth, 1, 31-34. https://doi.org/10.1016/j.oneear.2019.08.004

Oliver-Smith, A. (2005). 'Communities after Catastrophe' in S.E. Hyland (ed.). Community Building in the Twenty-First Century (pp. 45-70). Santa Fe, NM: School of American Research Press.

Pigott-McKellar, A.E., McNamara, K.E., Nunn, P.D., \& Watson, J.E.M. (2019). What are the barriers to successful community-based climate change adaptation? A review of grey literature. Local Environment, 24(4), 374-390. https://doi.org/10.1080/13549839.2019.1580688

Platteau, J.-P. (2004). Monitoring Elite Capture in Community-Driven Development. Development and Change, 35(2), 223-246. https://doi.org/10.1111/j.1467-7660.2004.00350.x Reid, H. (2016). Ecosystem- and community-based adaptation: Learning from communitybased natural resource management. Climate and Development, 8(1), 4-9. https://doi.org/10.1080/17565529.2015.1034233

Remling, E., \& Veitayaki, J. (2016). Community-based action in Fiji's Gau Island: A model for the Pacific? International Journal of Climate Change Strategies and Management, 8(3), 375-398. https://doi.org/10.1108/IJCCSM-07-2015-0101 
Sekine, H., Fukuhara, K., Uraguchi, A., Knee Tan, C., Nagai, M. and Okada, Y., 2009. The Effectiveness of Community-based Adaptation (CBA) to Climate Change: From the Viewpoint of Social Capital and Indigenous Knowledge. GEIC Working Paper Series 2009001.

Titz, A., Cannon, T., \& Krüger, F. (2018). Uncovering 'Community': Challenging an Elusive Concept in Development and Disaster Related Work. Societies, 8(3), 71-99. https://doi.org/10.3390/soc8030071

Vaioleti, T.M. (2006). Talanoa research methodology: a developing position on pacific research, Waikato Journal of Education, 12, pp. 21-34. https://doi.org/

Warrick, O. (2009). 'Ethics and methods in research for community-based adaptation: reflections from rural Vanuatu', in H. Ashley, N. Kenton \& A. Milligan (eds.). Participatory learning and action 60: Community-based adaptation to climate change (pp. 76-87). London: International Institute of Environment and Development (IIED).

Warrick, O., Aalbersberg, W., Dumaru, P., McNaught, R., \& Teperman, K. (2017). The 'Pacific Adaptive Capacity Analysis Framework': Guiding the assessment of adaptive capacity in Pacific island communities. Regional Environmental Change, 17(4), 1039-1051. https://doi.org/10.1007/s10113-016-1036-X

Westoby, P., \& Dowling, G. (2013). Theory and Practice of Dialogical Community Development: International Perspectives. London and New York: Routledge.

Westoby, R., McNamara, K. E., Kumar, R., \& Nunn, P. D. (2019). From community-based to locally led adaptation: Evidence from Vanuatu. Ambio. https://doi.org/10.1007/s13280-01901294-8

Yates, J. (2014). Power and politics in the governance of community-based adaptation. In J. Ensor, R. Berger, \& S. Huq (Eds.), Community-based Adaptation to Climate Change: 
Emerging Lessons (pp. 13-34). Practical Action Publishing.

https://doi.org/10.3362/9781780447902.002

Young, I. M. (1990). Justice and the Politics of Difference. Princeton, NJ and Woodstock, Oxfordshire: Princeton University Press. 


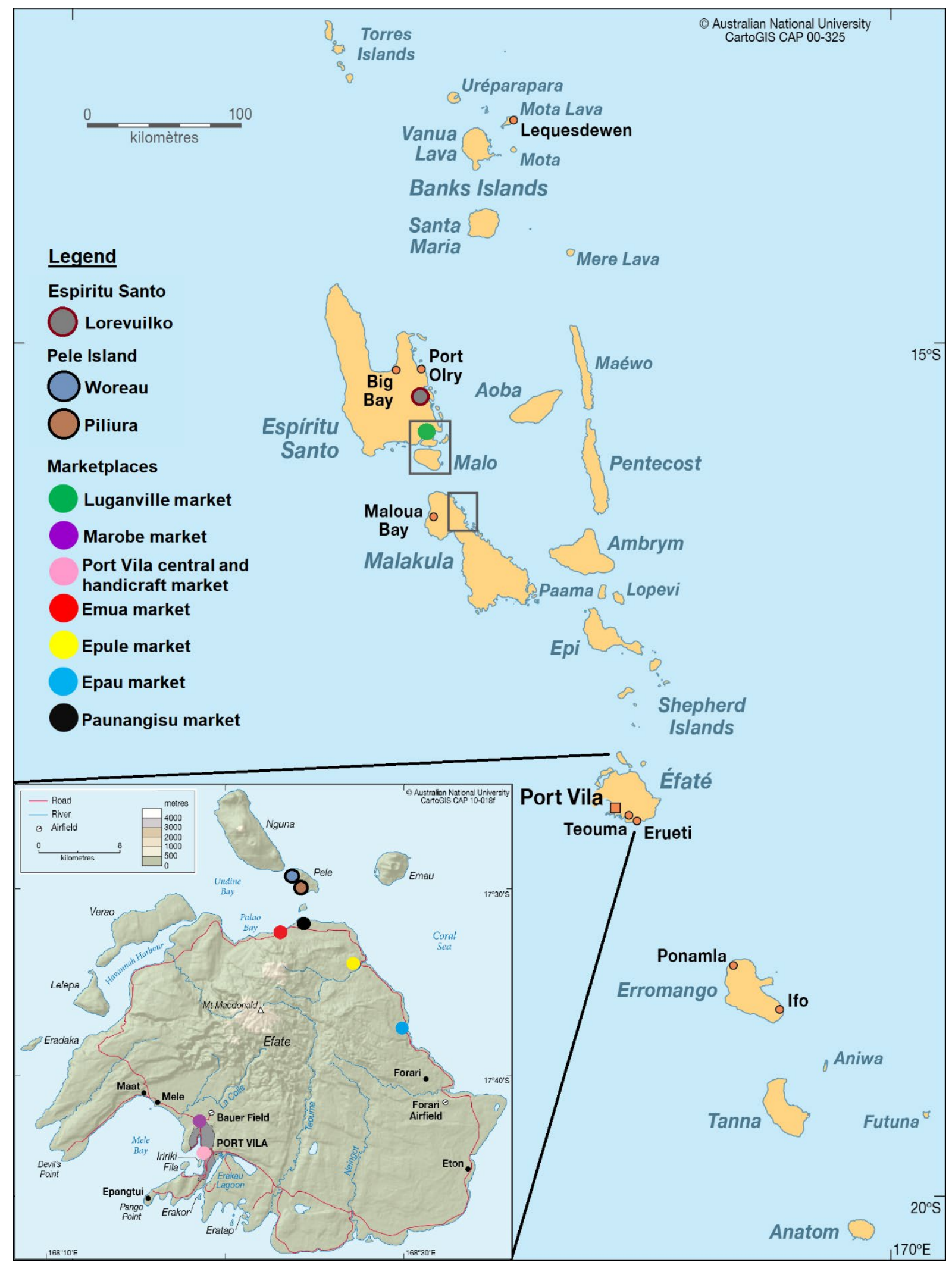

Figure 1: Map showing Vanuatu and the approximate locations of study sites.

Source: Adapted from ANU (2018a) and ANU (2018b) 